\title{
Routine Extraction of The Patient Receiving Antiplatelet Drug - A Review of Literature
}

\author{
Abhisek Das ${ }^{2}$, Prof.(Dr.) Sudip Chakraborty ${ }^{1}$ (MDS) \\ ${ }^{1}$ Professor, Department Of Oral \&Maxillofacial Surgery, Guru Nanak Institute Of Dental Science \& \\ Research, Panihati, Kolkata, \\ ${ }^{2} 3^{r d}$ Year PGT, Department Of Oral \&Maxillofacial Surgery, Guru Nanak Institute Of Dental \\ Science \&Research, Panihati, Kolkata,
}

\begin{abstract}
Cardiac patients on aspirin therapy may require extractions for their diseased teeth. It is a common practice among physicians and treating surgeons to stop aspirin prior to tooth extraction because of fear of bleeding complications. This practice often predisposes the patient to adverse thromboembolic events. This practice is based on theoretical risk of bleeding and on isolated case reports of excessive bleeding with aspirin therapy. The current consensus and recommendations are in favor of continuing aspirin therapy during simple tooth extraction as the bleeding complication incidence is very less and if it occurs can be controlled efficiently with local hemostasis measures.
\end{abstract}

Keywords: Antiplatelet, Aspirin, Clopidogrel, Extraction, Hemostasis

\section{Introduction}

Arterial and venous thromboses are major causes of morbidity and mortality rates. Arterial thrombosis is the most common cause of acute myocardial infarction (MI), ischemic stroke, and limb gangrene, whereas deep-vein thrombosis (DVT) leads to pulmonary embolism (PE), which can be fatal, and to the post-phlebitic syndrome. Most arterial thrombi are superimposed on disrupted atherosclerotic plaque \& this material then triggers platelet aggregation and fibrin formation, which results in the generation of a platelet-rich thrombus that can temporarily or permanently occlude blood flow. ${ }^{1}$

Arterial thrombi are rich in platelet. In healthy vasculature, circulating platelets are maintained in an inactive state by nitric oxide (NO) and prostacyclin released by endothelial cells lining the blood vessels. In addition, endothelial cells also express CD39 which degrades ADP released from activated platelets when the vessel wall is damaged, release of these substances is impaired and sub-endothelial matrix is exposed. Platelets adhere to exposed collagen via $\alpha 2 \beta 1$ and glycoprotein (GP)V1 and to von Willebrand factor (vWF) via GPIb $\alpha$ and GPIIb/IIIa ( $\alpha \mathrm{IIb} \beta 3$ ) -receptors that are constitutively expressed on the platelet surface. Adherent platelets undergo a change in shape, secrete ADP from their dense granules, and synthesize and release thromboxane A 2. Released ADP and thromboxane A 2activate ambient platelets and recruit them to the site of vascular injury. ${ }^{1}$

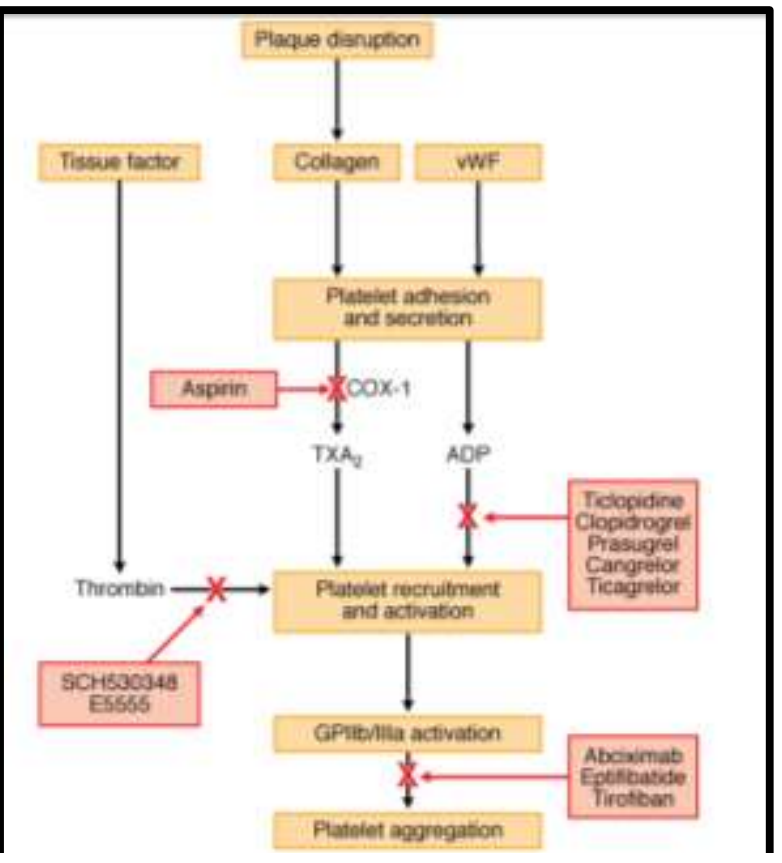


Aspirin was developed in 1897 and is one of theworld's safest and cheaper drugs with proven efficiency for over 100 years. ${ }^{2}$ A general practitioner in Glendale, California, named Lawrence Craven reported that daily low-dose aspirin has preventive role against myocardial infarction and stroke. He prescribed his 400 patients low-dose aspirin. None of his patients developed myocardial infarction for a period of 2 years (19481950). ${ }^{3}$ This was probably the first attempt to use aspirin to prevent myocardial infarction. ${ }^{2}$

\section{Antiplatelet Dose of Aspirin}

Aspirin is effective as antiplatelet drug at much lower doses than that required for analgesic and antiinflammatory functions. ${ }^{4}$ Antiplatelet activity of aspirin has been seen even at dose as low as $40 \mathrm{mg} / \mathrm{day} .{ }^{5}$ The antiplatelet properties are effective up to $320 \mathrm{mg}$ daily dose. In fact, doses of aspirin >320mg/day may even decrease the effectiveness as antiplatelet agent due to inhibition of prostacyclin production. Various evidence based studies recommended aspirin in the range of $75-100 \mathrm{mg} /$ day for the prophylaxis against serious vascular events in high risk patients. ${ }^{4,6}$ However, recent randomized clinical trial indicates that $160 \mathrm{mg} /$ day is the optimal dose of aspirin to prevent myocardial infarction and stroke. ${ }^{7}$ In clinical situations where immediate antithrombotic effect is required (such as unstable angina, acute myocardial infarction, or stroke), a loading dose of $300 \mathrm{mg}$ is recommended.Most frequently recommended doses of aspirin for prevention of myocardial infarction and stroke are 81,160 , and $325 \mathrm{mg}$ /day in the United States, whereas, in Europe and other countries, these doses are 75,150 , and $300 \mathrm{mg} /$ day. $^{7}$

Antiplatelet agents - principally aspirin and Clopidogrel, used alone or in combination - have been shown to reduce the risk of myocardial infarction (MI), ischaemic stroke, and cardiovascular death in patients with unstable angina, acute coronary syndromes (ACS), and ST-elevation MI (STEMI).In patients at risk, aspirin is recommended as life-long therapy and Clopidogrel is recommended for periods ranging from 1 to 12 months, or as a life-long substitute for aspirin in patients in whom aspirin is contraindicated.As a result, antiplatelet agents have become essential components of the treatment of these conditions. The most serious adverse effect associated with use of antiplatelet agents is bleeding. This raises the question of whether and, if so, when to discontinue antiplatelet therapy in patients who need surgery or diagnostic procedures that carry a risk of tissue injury. When platelets activity is altered, a longer time period is required to stop bleeding from a cut surface because of alteration in primary hemostasis mediated by platelet plug formation. ${ }^{8}$

In 2005, Burger et al. reviewed 474 studies regarding the impact of low-dose aspirin on surgical blood loss. They stated that, patients on aspirin, the average risk of intraoperative bleeding increases by a factor of $1.5 .^{9}$

\section{Risk of Stopping Aspirin Therapy prior to Surgery}

It was recommended traditionally to stop the aspirin 7-10 days prior to invasive surgical procedure. However, there is scientific evidence which showed that stopping antiplatelet therapy is associated with a progressive recovery of platelet function and with a potential risk of rebound of thromboembolic vascular events. On stopping aspirin, there is excessive thromboxane A2 activity and decreased fibrinolytic activity.Similarly, Ferrari et al. ${ }^{11}$ and Chassot et al. ${ }^{12}$ suspected the existence of a biological platelet rebound phenomenon on interruption of aspirin therapy, thus creating a prothrombotic state which may ultimately cause fatal thromboembolic events. The adverse consequences of arterial thromboembolism are much more serious, as approximately $20 \%$ of these episodes are fatal and $40 \%$ episodes can lead to serious permanent disability. ${ }^{13}$ In specific isolated circumstances, if stopping aspirin therapy is essential, it should be limited to 3 or fewer days. Risk of thromboembolic events increased considerably if aspirin therapy is discontinued between 4 and 30 days.Retrospective studies showed potential risk of fatal thromboembolic events like myocardial infarction and stroke on stopping aspirin therapy. ${ }^{10,11,14}$ The estimated risk of thromboembolic event if aspirin is stopped is approximately 1 in 21,448 cases.In 2000, Collet et al. performed retrospective analysis of 475 patients admitted to the hospital with the diagnosis of myocardial infarction. Eleven patients stopped aspirin therapy within 15 days prior to general surgical procedure. Another nine patients stopped aspirin 3 days prior to elective surgical procedures, one of which was a dental surgical procedure. This dental patient was stable and asymptomatic for a period of 10 years with continued use of aspirin.Unfortunately, myocardial infarction occurred 10 days after stopping aspirin therapy. ${ }^{16}$

\section{Debate Related To Timing For Stopping Aspirin Therapy}

Aspirin alters the cyclooxygenase pathway and inhibits platelet activity. The effect of aspirin on platelets is irreversible. The effect of aspirin starts within 1 hour of ingestion and lasts for 7-10 days, that is, life span of a platelet. ${ }^{17,18}$ Therefore, traditionally it was recommended to stop aspirin therapy 7-10 days prior to invasive surgical procedure.In 1992, Conti in an editorial mentioned that there is no need to stop aspirin prior to invasive surgical procedure if bleeding time is within normal limit. ${ }^{24}$ Little et al. suggested that aspirin affected platelets did not cause significant bleeding complications unless the bleeding time is greater than 20 minutes. $^{25}$ Similarly, Sonksen et al. $^{26}$ and Gaspar et al. ${ }^{27}$ claimed that there is no significant intraoperative and 
postoperative bleeding after dental extractions as long as prolongation in bleeding time remains within acceptable limit (bleeding time up to 20 minutes).

In 1999, Sonksen et al. performed a clinical study on 52 healthy volunteers taking 7-day course of lowdose aspirin. They found that, after stopping the aspirin, the bleeding time (BT) was less than 10 minutes within 48 hours of stopping the aspirin therapy. Hence, they stated that withdrawal of aspirin for $\geq 5$ days appears erroneous.In 2000, Wahl recommended that aspirin should be discontinued for 3 days only. The rationale for such recommendation is that, after 3 days of interruption of aspirin, sufficient number of newer platelets (which are not affected by aspirin) will be present in the circulation for effective hemostasis. In 2002, According to Daniel et al. ${ }^{29}$ and Sonis et al $(1996)^{30}$, antiplatelet therapy should be stopped 7 days preoperatively to minimize the risk of bleeding during surgery. Sonis et al. further stated that only the production of newer platelets will be able to overcome the inhibiting effect of aspirin. Therefore, stopping aspirin only for few days does not reverse the aspirin inhibition.In 2003, Fijnheer et al. in a review article mentioned that there is scarcity of literature regarding cataract, dermatologic, ear, nose, and throat, and dental surgeries involving patients on aspirin medication.In 2005, Ferrari et al. mentioned that, in specific isolated circumstances, if stopping aspirin therapy is essential, it should be limited to 3 or fewer days. Medeiros et al. proposed that antiplatelet should be stopped 24 to 48 hours prior to surgery and restart $24-48$ hours after surgery. ${ }^{11}$

There is considerable conflicting opinion regarding the exact time of stopping aspirin prior to invasive surgical procedure. Various authors recommended to stop aspirin preoperatively. The timing to stop aspirin ranges between 24 hours to 7-10 days.On the contrary some authors recommended not to stop aspirin preoperatively.Few studies in the literature advocated stopping aspirin therapy prior to surgical procedure because of increased risk of bleeding. However, if the aspirin therapy is altered or discontinued, there is increased risk of thromboembolic events.

\section{Increased Bleeding With Use Of Aspirin Therapy}

In 1996, Scher advocated stopping aspirin therapy before any elective surgery if it is not an emergency procedure. Continuous diffuse bleeding was present after surgery in patients taking aspirin therapy.In 1997, Thomason et al. reported a case of excessive bleeding after a gingivectomy (in maxillary anterior segment) in a patient taking aspirin $150 \mathrm{mg} /$ day. In this patient, platelet transfusion was required to control the excessive bleeding.In 2002, Schrodi et al. found increased bleeding on probing in patients who consumed aspirin in a dose of $325 \mathrm{mg}$ /day for 7 days.In 2004, Royzman et al. studied the effect of $81 \mathrm{mg}$ and 325mg dose of aspirin on bleeding on probing. Fifty-four patients were divided into 3 groups. The first group consumed $81 \mathrm{mg}$ aspirin daily for 7 days, second group consumed $325 \mathrm{mg}$ aspirin daily for 7 days, and the third group consumed placebo for 7 days. They concluded that there is increased bleeding on probing in aspirin group, which can lead to impairment in diagnostic assessment and decision making for treatment planning.In 2008, Elad et al. reported a case of severe bleeding episode following nonsurgical periodontal treatment in a patient taking dual antiplatelet therapy (aspirin 100mg plus Clopidogrel $75 \mathrm{mg} /$ day). Preoperative values of platelet count and international normalized ratio (INR) were in normal range. Severe life threatening haemorrhage occurred postoperatively leading to haemorrhagic shock. ${ }^{35}$

\section{Safety of Continued Aspirin Therapy prior to Tooth Extraction}

In 1999, Gaspar et al. concluded that ambulatory oral surgical procedures can be performed in patients on aspirin therapy as hemostasis posed no problem. Hence, they recommended continuation of aspirin therapy without interruption prior to oral surgical procedures.In 2000, Matocha stated that risk of bleeding after dental extractions is rare in patients on low-dose aspirin therapy \& it does not exceed 0.2 to 2.3\%.In 2000, Ardekian et al. conducted a prospective study to evaluate the risk of bleeding after tooth extraction with the use of aspirin $100 \mathrm{mg} /$ day. Suture and pressure pack had been used to achieve hemostasis in all patients. Additional use of local application of tranexamic acid pressure pack was restricted for patient with increased intraoperative bleeding. The authors found bleeding complication in patients who stopped aspirin \& in patients on continued aspirin therapy. The bleeding incidence among two groups was comparable and the hemostasis was easily achieved with local hemostatic measures. ${ }^{37}$

In 2005, Madan et al. performed minor oral surgical procedures in patients on low-dose aspirin therapy (75-100mg/day). The surgical procedures performed were simple and surgical extractions and implant placement. Suturing and pressure pack for 30 minutes had been used as hemostatic measure in all the cases. After 30 minutes, patients were reassessed for hemostasis. Intraoperative blood loss $>30 \mathrm{~mL}$ was considered excessive. The results showed that only 1 patient after $3^{\text {rd }}$ molar extraction showed excessive bleeding intraoperatively which was easily managed by pressure pack soaked in $1 \%$ feracrylum solution. There was no postoperative bleeding in any case. These authors concluded that most minor oral surgical procedures can be carried out safely without interrupting long-term low-dose aspirin therapy. ${ }^{38}$ 
In 2006 , Hemelik et al. performed 151 tooth extractions in 65 patients on $100 \mathrm{mg} /$ day aspirin therapy. The frequency of postoperative bleeding was $1.54 \%$ as compared to $1.59 \%$ in healthy control group. All bleeding episodes were handled easily. They concluded that there is no need to stop 100mg/day aspirin prior to dental extractions.In 2007, Brennan et al. reviewed the literature regarding the management of patients on aspirin requiring oral surgical procedures \& recommended continuation of aspirin during dental extractions based on results of studies with high level of evidences.In 2007, American Heart Association, American College of Cardiology, Society for Cardiovascular Angiography and Interventions, American College of Surgeons, and American Dental Association recommended either continuing aspirin and Clopidogrel therapy for minor oral surgical procedures in patients who have coronary artery stents or delaying treatment until prescribed regimen will be completed.In 2008, Krishnan et al. in a prospective clinical study performed extraction procedures on patients taking aspirin, on patients who stopped aspirin preoperatively, and in normal patients[25 patients in each group]. Simple intra-alveolar extractions were performed and hemostasis was achieved with wet gauze pressure pack for 30 minutes \& they concluded that patient continuing aspirin therapy can undergo routine dental extractions without increased risk of excessive or prolonged bleeding.

In 2008, Brennan et al. performed a double blind randomized controlled study in healthy patients. A total of 36 healthy patients were randomly divided into two groups. Group 1 patients $(n=17)$ were given aspirin $325 \mathrm{mg} /$ day two days preoperatively and continued for further 2 days after extraction (total 4 days). Group 2 patients $(n=19)$ received placebo with similar time schedule as followed in Group 1. Single tooth extractions were performed in both groups. The two groups were similar with respect to baseline information, site of extraction, extraction difficulty, extraction time, and compliance. The primary outcome was intraoral bleeding time and the secondary outcome was bleeding complication.Although intraoral bleeding time was greater in aspirin group, it is not statistically significant. Also, there was no statistically significant difference between two groups with respect to postoperative bleeding. They concluded that there is no indication to stop aspirin in patients requiring single tooth extraction. ${ }^{42}$

In 2009, Nape nas et al. conducted a retrospective analysis to evaluate the risk of bleeding complications in patients on single or dual antiplatelet therapy undergoing invasive oral surgical procedures including dental extractions. They concluded that risk of stopping antiplatelet therapy and predisposing the patient to thromboembolic events far overweighed the negligible risk of bleeding from dental procedures.In 2009 , Nooh performed simple and surgical extractions in patients on aspirin therapy ( $81 \mathrm{mg} / \mathrm{day})$. Normal patients that had undergone the same procedures served as control group. Wet gauze pressure pack for 30 minutes and figure of 8 suturing were adequate to achieve hemostasis in simple and surgical extractions, respectively. Patients on aspirin therapy undergoing surgical procedure exhibited mild oozing easily controlled by pressure packs alone. Therefore, the author concluded that patients taking $81 \mathrm{mg}$ of aspirin can undergo dental extractions and there is no clinically significant increased bleeding risk. ${ }^{44}$

In 2010, Ca nigral et al. conducted a study involving simple and surgical extractions in patients on antithrombotic therapy \& therapy comprises aspirin, Clopidogrel, aspirin + Clopidogrel, nonsteroidal antiinflammatory drugs (NSAIDs), or low molecular weight heparin (LMWH). In92\% of instances, bleeding was stopped within 10 minutes with pressure alone. Only $8 \%$ of cases of moderate hemorrhage were easily managed by local hemostatic measures.In 2010, Duygu et al. performed a clinical study to assess the effect of antiplatelet drugs on risk of bleeding complications after teeth extractions. Simple dental extractions were performed in experimental group patients on continued aspirin therapy $(n=25)$ and control group patients who stopped aspirin 7 days prior to extractions $(n=19)$. The experimental group patients were on aspirin dose in the range of 75-300mg. Method to achieve hemostasis ranges from wet gauze pressure pack, locally applied tranexamic acid, to the use of gelatin sponge and suturing. Local hemostatic measures were able to maintain primary hemostasis in all cases. There were no intraoperative and postoperative bleeding complications in any case including the patients with prolonged BT of 12.3 minutes. There was no statistically significant difference between two groups with respect to postoperative bleeding complications. They concluded that there is no need for interruption of long-term aspirin therapy prior to dental extractions. ${ }^{46}$

In 2011, Medeiros et al. performed simple single tooth extraction (molar tooth) in patient on aspirin therapy. Sixty-three patients involved in the study were randomly divided into two groups. Group $\mathrm{S}$ patients $(n$ $=31)$ have suspended their aspirin therapy 7 days prior to extraction. Group NS patients $(n=32)$ have not suspended their aspirin therapy $(100 \mathrm{mg} /$ day) and undergone extraction. Suturing was used as a hemostatic measure in all the patients. Additional use of biological adhesive was restricted to those patients who showed increased intraoperative bleeding as compared to others. None of the patients exhibited any bleeding complication postoperatively. The results showed that mean ( \pm standard deviation) volume of blood loss per tooth extraction was $16.38 \pm 13.54 \mathrm{~mL}$ in group NS (aspirin not suspended) and $12.10 \pm 9.37 \mathrm{~mL}$ group S (aspirin suspended). Although the mean blood loss per tooth extraction was greater in group NS, this was not statistically significant. Based on these results, they concluded that there is no need to suspend aspirin therapy $(100 \mathrm{mg} /$ day $)$ prior to single molar extraction. ${ }^{47}$ 
In 2011, Lillis et al. performed a prospective study to compare the incidence of bleeding complications among patients taking aspirin monotherapy, Clopidogrel monotherapy, and dual therapy with both aspirin and Clopidogrel and patients not taking aspirin at all.Out of 643 patients enrolled in the study, 111 patients were on antiplatelet therapy: aspirin monotherapy $(n=42)$, Clopidogrel monotherapy $(n=36)$, and dual therapy with both aspirin and Clopidogrel $(n=33)$. Patients not taking any antiplatelet drugs serve as control $(n=532)$. Teeth were extracted by simple method in all the patients under local anesthesia. To achieve hemostasis, extraction sockets were compressed with digital pressure for 2 minutes followed by sterile gauze pressure pack for 30 minutes. After 30 minutes, patients were reevaluated to look for any bleeding.If present, then a piece of oxidized cellulose (Surgicel) was placed in the socket and suturing was done followed by sterile gauze pressure pack for 30minutes and reevaluation. Patients were discharged after establishing hemostasis.

The results showed that greater number of patients on dual antiplatelet therapy showed prolonged immediate bleeding when compared to control healthy patient group and the difference is statistically significant. However, when incidence of prolonged immediate bleeding in patients on either aspirin monotherapy or Clopidogrel monotherapy is compared with control group, the difference was not statistically significant. There is statistically significant difference when incidence of prolonged immediate bleeding was compared between dual antiplatelet therapy with aspirin monotherapy and Clopidogrel monotherapy. No patient exhibited late bleeding. Although there is greater incidence of prolonged immediate bleeding in dual antiplatelet therapy group, hemostasis was achieved easily by local hemostatic measures.

Therefore, they concluded that, the patient should not be predisposed to risk of thromboembolism by stopping either anti-platelet monotherapy or dual therapy. ${ }^{48}$

In 2012, Park et al. performed a prospective clinical study to evaluate the safety of dental extractions in patients on continued antiplatelet therapy with multiple drugs.59 patients were on dual aspirin (100 or $200 \mathrm{mg} /$ day) + Clopidogrel 75mg/day therapy and 41 patients were on triple antiplatelet therapy (aspirin 100 or $200 \mathrm{mg}$ /day plus Clopidogrel $75 \mathrm{mg}$ /day plus cilostazol $100 \mathrm{mg} /$ day).A hundred patients not taking any antiplatelet agents served as controlgroup. Only 3 patients exhibited post-operative bleeding (1 on dual, 1 on triple anti-platelet therapy and 1 not taking any anti-platelet drug). All the episodes of bleeding were easily controlled by pressure application by patients themselves. The authors concluded that dental extractions can be performed safely in patients on multiple antiplatelet agents.In 2012, Badal et al. stated that current researches suggested that there is no indication to stop aspirin therapy prior to invasive dental procedures as any postoperative bleeding if present can be easily managed by local hemostatic measures. ${ }^{50}$

In 2012, Shah et al. performed a prospective study to compare the incidence of bleeding complications among patients taking aspirin and those not taking aspirin at all. A total of 254 patients were enrolled in the study. Group 1 patients $(n=127)$ were taking $75-150 \mathrm{mg}$ /day aspirin and continued it prior to extraction. Group $2(n=127)$ patients constitute the control group who were not taking any aspirin dose prior to extraction. One tooth was extracted by simple method in each patient of both groups. The results showed that 5 patients $(3.93 \%)$ in aspirin group and 3 patients $(2.36 \%)$ in control group presented with prolonged immediate bleeding which was managed by additional hemostatic measures. The difference was not statistically significant. Also 2 patients $(1.57 \%)$ in aspirin group and 1 patient $(0.78 \%)$ in control group presented with late bleeding at 12 hours postoperatively. This difference was again not statistically significant. Hemostasis was achieved easily by patients themselves with the help of pressure pack at home. None of the patients exhibited very late bleeding. They concluded that it is a safe practice to perform simple extraction of 1 tooth in patients taking 75$150 \mathrm{mg}$ aspirin daily. ${ }^{51}$

In 2013, Verma et al. performed a comparative study to evaluate the incidence of bleeding complications in patient on aspirin therapy. The study comprises three groups with 30 patients in each group. Group 1 patients on antiplatelet dose of aspirin (75-325mg/day) continued it during extraction, Group 2 patients stopped their antiplatelet therapy, and Group 3 comprises normal patients not taking any antiplatelet drugs. Single tooth was extracted by intra-alveolar method in each group and the hemostasis was achieved in all cases by wet gauze pressure pack. The use of additional local hemostatic agents was restricted in case of bleeding complication. The authors concluded that single tooth extraction by intra-alveolar method in patient on continued aspirin therapy is a safe procedure.

\section{Discussion}

Decision to continue or stop the antiplatelet therapy is like weighing risk of thromboembolic event against risk of bleeding. Before decision making, some factors need consideration. These factors are patient's inherent risk factors for bleeding, additional ongoing treatment which increases the bleeding risk, invasive potential of the surgical procedure, and potential risk of thromboembolic event if antiplatelet therapy is stopped. In addition to these, previous history of bleeding episode, haemorrhagic peptic ulcers, or haemorrhagic stroke increases possibility of bleeding. Schrodi et al. ${ }^{33}$ and Royzman et al. ${ }^{34}$ reported increased bleeding on probing in patients on aspirin therapy. 
Similarly, Lillis et al. ${ }^{49}$ and Shah et al. ${ }^{52}$ reported that bleeding complications after tooth extraction (in patients on aspirin) were slightly higher if tooth extraction was performed because of periodontitis as compared to dental caries.Scher found continuous diffuse bleeding after surgery in patients taking aspirin therapy. ${ }^{22}$ However, the patients involved in their study were taking much higher doses of aspirin.

\section{TABLE}

\begin{tabular}{|c|c|c|c|}
\hline \multirow{2}{*}{$\begin{array}{l}\text { Risk of stent thrombosis } \\
\text { (to be evaluated with the } \\
\text { cardiologist) }\end{array}$} & \multicolumn{3}{|c|}{$\begin{array}{c}\text { Haemorrhagic risk of the invasive or surgical procedure (to be evaluated with the } \\
\text { physician or the surgeon) }\end{array}$} \\
\hline & Major & Intermediate & Minor \\
\hline \multirow[t]{2}{*}{ Major } & $\begin{array}{l}\text { Post pone intervention } 6 \\
\text { months to } 1 \text { year after } \\
\text { stent positioning }\end{array}$ & $\begin{array}{l}\text { Post pone intervention } 6 \\
\text { months to } 1 \text { year after } \\
\text { stent positioning }\end{array}$ & \multirow[t]{2}{*}{$\begin{array}{l}\text { Maintain aspirin an } \\
\text { Clopidogrel }\end{array}$} \\
\hline & $\begin{array}{c}\text { If impossible: stop aspirin } \\
\text { - Clopidogrel } 5 \text { days, or } \\
\text { stop aspirin - Clopidogrel } \\
10 \text { days (max) and } \\
\text { substitute }\end{array}$ & $\begin{array}{l}\text { If impossible: maintain } \\
\text { aspirin, stop Clopidogrel } \\
5 \text { days }\end{array}$ & \\
\hline Moderate & $\begin{array}{l}\text { stop aspirin - Clopidogrel } \\
5 \text { days, or stop aspirin - } \\
\text { Clopidogrel } 10 \text { days } \\
\text { (max) and substitute }\end{array}$ & $\begin{array}{l}\text { Maintain aspirin, stop } \\
\text { Clopidogrel } 5 \text { days }\end{array}$ & $\begin{array}{l}\text { Maintain aspirin and } \\
\text { Clopidogrel, or maintain } \\
\text { aspirin and stop } \\
\text { Clopidogrel } 5 \text { days }\end{array}$ \\
\hline
\end{tabular}

Recommendations of the French Society of Anesthesiology and Intensive Care (SFAR),Br J Anaesth 2006;97:580-582

\section{Conclusion}

Extraction is one of the most common procedures performed in oral surgery. Surgical procedures performed on the patients must be based on sound scientific knowledge of literature. Based on the review of literature, it can be concluded that current recommendations and consensus are in favor of not stopping antiplatelet dose of aspirin prior to tooth extraction. It must be emphasized that appropriate use of local hemostatic measures should always be considered whenever indicated. There is no justification to predispose the patient to the risk of thromboembolism at the expense of minor bleeding which can be easily controlled.

[1]. Principles of internal medicine, Harrison's, 18the edition

[2]. A. J. Kumar, M. M. Kumari, N. Arora, and A. Haritha, "Is antiplatelet therapy interruption a real clinical issue? Its implications in dentistry and particularly in periodontics," Journal of Indian Society of Periodontology, vol. 13, no. 3, pp. 121-125, 2009.

[3]. L. L. Craven, "Acetylsalicylic acid, possible preventive of coronary thrombosis," Annals of Western Medicine and Surgery, vol. 4no. 2, p. 95, 1950

[4]. C. Patrono,G. Ciabarroni, P. Patrignani et al., "Clinical pharmacology of platelet cyclooxygenase inhibition," Circulation, vol.72, no. 6, pp. 1177-1184, 1985 .

[5]. M. T. Brennan, R. L. Wynn, and C. S. Miller, "Aspirin and bleeding in dentistry: an update and recommendations," OralSurgery, Oral Medicine, Oral Pathology, Oral Radiology andEndodontology, vol. 104, no. 3, pp. 316-323, 2007.

[6]. Antithrombotic Trialists' Collaboration, "Collaborative metaanalysis of randomized trials of antiplatelet therapy for prevention of death, myocardial infarction, and stroke in high risk patients," British Medical Journal, vol. 324, no. 7329, pp. 71-86, 2002.

[7]. J. E. Dalen, “Aspirin to prevent heart attack and stroke: what's the right dose?" American Journal of Medicine, vol. 119, no. 3, pp. 198-202, 2006.

[8]. C. D. Owens and M. Belkin, "Thrombosis and coagulation: operative management of the anticoagulated patient," Surgical Clinics of North America, vol. 85, no. 6, pp. 1179-1189, 2005.

[9]. W. Burger, J.-M. Chemnitius, G. D. Kneissl, and G. R"ucker, "Low-close aspirin for secondary cardiovascular preventioncardiovascular risks after its perioperative withdrawal versus bleeding risks with its continuation-review and metaanalysis," Journal of Internal Medicine, vol. 257, no. 5, pp. 399-414, 2005.

[10]. J.-P. Collet and G. Montalescot, "Premature withdrawal and alternative therapies to dual oral antiplatelet therapy," EuropeanHeart Journal Supplements, vol. 8, pp. G46-G52, 2006.

[11]. E. Ferrari, M. Benhamou, P.Cerboni, and B. Marcel, "Coronary syndromes following aspirin withdrawal: a special risk for late stent thrombosis," Journal of the American College of Cardiology, vol. 45, no. 3, pp. 456-459, 2005.

[12]. P.-G. Chassot, A. Delabays, and D. R. Spahn, "Perioperative antiplatelet therapy: the case for continuing therapy in patients at risk of myocardial infarction," British Journal of Anaesthesia, vol. 99, no. 3, pp. 316-328, 2007.

[13]. C. S. Anderson, K. D. Jamrozik, R. J. Broadhurst, and E. G. Stewart-Wynne, "Predicting survival for 1 year among different subtypes of stroke: results from The Perth Community Stroke Study," Stroke, vol. 25, no. 10, pp. 1935-1944, 1994.

[14]. I. Sibon and J.-M. Orgogozo, “Antiplatelet drug discontinuation is a risk factor for ischemic stroke,” Neurology, vol. 62, no. 7, pp. 1187-1189, 2004

[15]. O. Kovich and C. C. Otley, "Thrombotic complications related to discontinuation of warfarin and aspirin therapy perioperatively for cutaneous operation," Journal of the American Academy of Dermatology, vol. 48, no. 2, pp. 233-237, 2003. 
[16]. J.-P. Collet, D. Himbert, and P. G. Steg, "Myocardial infarction after aspirin cessation in stable coronary artery disease patients," International Journal of Cardiology, vol. 76, no. 2-3, pp. 257-258, 2000.

[17]. J. C. Merritt and D. L. Bhatt, "The efficacy and safety of perioperative antiplatelet therapy," Journal of Thrombosis and Thrombolysis, vol. 13, no. 2, pp. 97-103, 2002.

[18]. A. I. Schafer, "Effects of nonsteroidal anti-inflammatory drugs on platelet function and systemic hemostasis," Journal of Clinical Pharmacology, vol. 35, no. 3, pp. 209-219, 1995.

[19]. C. J. E.Watson, A. M. Deane, P. T. Doyle, and K. N. Bullock, "Identifiable factors in post-prostatectomy haemorrhage: the role of aspirin," British Journal of Urology, vol. 66, no. 1, pp. 85- 87, 1990.

[20]. L. Kitchen, R. B. Erichson, and H. Sideropoulos, "Effect of drug induced platelet dysfunction on surgical bleeding," American Journal of Surgery, vol. 143, no. 2, pp. 215-217, 1982.

[21]. C. R. Conti, "Aspirin and elective surgical procedures," Clinical Cardiology, vol. 15, no. 10, pp. 709-710, 1992.

[22]. K. S. Scher, "Unplanned reoperation for bleeding," American Surgeon, vol. 62, no. 1, pp. 52-55, 1996.

[23]. J. A. Speechley and F. P. Rugman, "Some problems with anticoagulants in dental surgery," Dental Update, vol. 19, no. 5, pp. $204-$ 206,1992

[24]. C. R. Conti, “Aspirin and elective surgical procedures (editor's note)," Clinical Cardiology, vol. 15, no. 10, pp. 709-710, 1992.

[25]. J. W. Little, C. S. Miller, R. G. Henry, and B. A. McIntosh, "Anti thrombotic agents: implications in dentistry," Oral Surgery, Oral Medicine, Oral Pathology, Oral Radiology, and Endodontics, vol. 93, no. 5, pp. 544-551, 2002.

[26]. J. R. Sonksen, K. L. Kong, and R. Holder, "Magnitude and time course of impaired primary hemostasis after stopping chronic low and medium dose aspirin in healthy volunteers," British Journal of Anaesthesia, vol. 82, no. 3, pp. 360-365, 1999.

[27]. R. Gaspar, L. Ardekian, B. Brenner, M. Peled, and D. Laufer, "Ambulatory oral procedures on low-dose aspirin," Harefuah, vol. 136, no. 2, pp. 108-110, 1999.

[28]. M. J. Wahl, "Myths of dental surgery in patients receiving anticoagulant therapy," The Journal of the American DentalAssociation, vol. 131 , no. 1 , pp. $77-81,2000$

[29]. N. G. Daniel, J. Goulet, M. Bergeron, R. Paquin, and P.-E. Landry, "Antiplatelet drugs: is there a surgical risk?" Journal of the Canadian Dental Association, vol. 68, no. 11, pp. 683-687, 2002.

[30]. S. T. Sonis, R. C. Fazio, L. Fang et al., PrincIplos e Pratica de Medicina Oral, Guanabara Koogan, Rio de Janeiro, Brazil, $2^{\text {nd }}$ edition, 1996.

[31]. R. Fijnheer, R. T. Urbanus, and H. K. Nieuwenhuis, "Withdrawing the use of acetylsalicylic acid prior to an operation usually not necessary," Nederlands Tijdschrift voor Geneeskunde, vol. 147, no. 1, pp. 21-25, 2003.

[32]. J. M.Thomason, R. A. Seymour, P.Murphy, K.M. Brigham, and P. Jones, "Aspirin-induced post-gingivectomy haemorrhage: a timely reminder," Journal of Clinical Periodontology, vol. 24, no. 2, pp. 136-138, 1997.

[33]. J. Schrodi, L. Recio, J. Fiorellini,H.Howell, M.Goodson, and N. Karimbux, "The effect of aspirin on the periodontal parameter bleeding on probing," Journal of Periodontology, vol. 73, no. 8, pp. 871-876, 2002.

[34]. D. Royzman, L. Recio, R. L. Badovinac et al., "The effect of aspirin intake on bleeding on probing in patients with gingivitis," Journal of Periodontology, vol. 75, no. 5, pp. 679-684, 2004.

[35]. S. Elad, T. Chackartchi, L. Shapira, and M. Findler, "A critically severe gingival bleeding following non-surgical periodontal treatment in patients medicated with anti-platelet," Journal of Clinical Periodontology, vol. 35, no. 4, pp. 342-345, 2008.

[36]. D. L. Matocha, "Postsurgical complications," Emergency Medicine Clinics of North America, vol. 18, no. 3, pp. 549-564, 2000.

[37]. L. Ardekian, R. Gaspar, M. Peled, B. Brener, and D. Laufer, "Does low-dose aspirin therapy complicate oral surgical procedures?" Journal of the American Dental Association, vol. 131, no. 3, pp. 331-335, 2000.

[38]. G. A.Madan, S. G.Madan, G.Madan, and A.D.Madan, "Minor oral surgery without stopping daily low-dose aspirin therapy: a study of 51 patients," Journal of Oral and Maxillofacial Surgery, vol. 63, no. 9, pp. 1262-1265, 2005.

[39]. M. Hemelik, G. Wahl, and B. Kessler, "Tooth extraction under medication with acetylsalicylic acid," Mund-Kiefer-und Gesichtschirurgie, vol. 10, no. 1, pp. 3-6, 2006.

[40]. C. L. Grines, R. O. Bonow, D. E. Casey Jr. et al., "Prevention of premature discontinuation of dual antiplatelet therapy in patients with coronary artery stents: a science advisory from the American Heart Association, American College of Cardiology, Society for Cardiovascular Angiography and Interventions, American College of Surgeons, and American Dental Association, with representation from the American College of Physicians," Circulation, vol. 115, no. 6, pp. 813-818, 2007.

[41]. B. Krishnan, N. A. Shenoy, and M. Alexander, "Exodontia and antiplatelet therapy," Journal of Oral and Maxillofacial Surgery, vol. 66, no. 10 , pp. 2063-2066, 2008.

[42]. M. T. Brennan, M. A. Valerin, J. L. Noll et al., “Aspirin use and post-operative bleeding from dental extractions,” Journal of Dental Research, vol. 87, no. 8, pp. 740-744, 2008.

[43]. J. J. Napennas, C. H. L. Hong, M. T. Brennan, S. L. Furney, P. C. Fox, and P. B. Lockhart, "The frequency of bleeding complications after invasive dental treatment in patients receiving single and dual antiplatelet therapy," Journal of the American Dental

a. Association, vol. 140, no. 6, pp. 690-695, 2009

[44]. N. Nooh, "The effect of aspirin on bleeding after extraction of teeth," Saudi Dental Journal, vol. 21, no. 2, pp. 57-61, 2009.

[45]. A. Ca nigral, F.-J. Silvestre, G. Cãnigral, M. Al'os, A. Garcia-Herraiz, andA. Plaza, "Evaluation of bleeding risk and measurementmethods in dental patients,"Medicina Oral, Patologia Oraly Cirugia Bucal, vol. 15, no. 6, pp. e863-e868, 2010.

[46]. G. Duygu, C. Ozcakir-Tomruk, N. Guler, and K. Sencift, "Assessment of effects of antiplatelet drugs on bleeding risk after teeth extractions," Biotechnology and Biotechnological Equipment, vol. 24, no. 3, pp. 2040-2043, 2010.

[47]. F. B. Medeiros, A. C. P. de Andrade, G. A. M. C. Angelis et al., "Bleeding evaluation during single tooth extraction in patients with coronary artery disease and acetylsalicylic acid therapy suspension: a prospective, double-blinded, and randomized study," Journal of Oral and Maxillofacial Surgery, vol. 69, no. 12, pp. 2949-2955, 2011.

[48]. T. Lillis, A. Ziakas, K. Koskinas, A. Tsirlis, and G. Giannoglou, "Safety of dental extractions during uninterrupted single or dual antiplatelet treatment," American Journal of Cardiology, vol. 108, no. 7, pp. 964-967, 2011.

[49]. M.-W. Park, S.-H. Her, J. B. Kwon et al., "Safety of dental extractions in coronary drug-eluting stenting patients without stopping multiple antiplatelet agents," Clinical Cardiology, vol. 35, no. 4, pp. 225-230, 2012.

[50]. S. Badal, S. Ahmed, R. Shrikanthan, and A. Badal, "Continuing antiplatelet therapy throughout dental procedures: a clinical dilemma," Journal of Interdisciplinary Dentistry, vol. 2, no. 1, pp. 15-19, 2012.

[51]. A. Shah, S. T. Shah, I. Shah, and Zia-Ur-Rehman, "Post extraction bleeding associated with long term maintenance dose of aspirin 75-150 mg,” Pakistan Oral and Dental Journal, vol. 32, no. 2, pp. 199-202, 2012.

[52]. G. Verma, A. K. Tiwari, and S. Chopra, "Aspirin and exodontias: a comparative study of bleeding complications with aspirin therapy," International Journal of Dental Science and Research, vol. 1, no. 2, pp. 50-53, 2013. 